\title{
CONCEPÇÕES DE HOMEM, SOCIEDADE E MUNDO DO TRABALHO EM PROJETOS DE FORMAÇÃO DE CURSOS DA ÁREA DA SAÚDE1
}

\author{
Hellen Cristina Sthal ${ }^{2}$ \\ Cátia Regina Assis Almeida Leal ${ }^{3}$
}

\begin{abstract}
Resumo
A reorientação da formação profissional em saúde no Brasil tem ganhado espaço crescente no debate científico. Buscou-se contribuir com esse debate investigando as concepções de homem e de sociedade que embasam os projetos de formação dos cursos de graduação da área da saúde da UFG - Regional Jataí, e a abordagem sobre o mundo do trabalho presente nesses projetos. Os dados, analisados, à luz do materialismo histórico-dialético, revelam concepções acríticas e individualistas de homem e de mundo/sociedade; e uma proposta de formação voltada, em grande parte, ao mercado de trabalho.
\end{abstract}

Palavras-chave: Educação; Formação profissional em saúde; Concepções de homem e sociedade.

\section{Resumen}

La reorientación de la formación profesional en salud en Brasil ha ganado un espacio cada vez mayor en el debate científico. Se buscó contribuir con el debate al investigar las concepciones de hombre y de sociedad que basan los proyectos de formación de los cursos de pregrado del área de salud de la UFG - Regional Jataí, y la perspectiva respecto al mundo del trabajo presentes en estos proyectos. Los datos analizados a la luz del materialismo histórico dialéctico revelan concepciones acríticas e individualistas de hombre y de mundo/sociedad; y una propuesta de formación, en gran parte, direcionada

al mercado de trabajo.

Palabras clave: Educación; Formación profesional en salud; Concepciones de hombre y de sociedad.

\footnotetext{
${ }_{1}^{1}$ DOI: https://doi.org/10.22409/tn.16i29.p4555

${ }^{2}$ Mestre em Educação. Professora do Curso de Enfermagem da Universidade Federal de Goiás UFG - Atualmente é Professora Assistente da UFG Regional Jataí, lotada no Curso de Graduação em Enfermagem. Membro do Núcleo de Estudos Sociedade, Educação e Cultura (NESEC) e do Núcleo de Estudo e Pesquisa em Gestão e Atenção à Saúde do Trabalhador (NEGEAST). hellen_sthal@hotmail.com

${ }^{3}$ Doutora em Educação. Professora do Curso de Educação Física e do Programa de PósGraduação em Educação da Universidade Federal de Goiás. Programa de Pós-Graduação em Educação da Regional Jataí da Universidade Federal de Goiás. - UFG - Regional Jataí. catiaassisleal@gmail.com
} 


\section{Introdução}

A medicina científica ocidental passou por um processo de rápido desenvolvimento, principalmente a partir do século XIX, gerando otimismo quanto ao poder da ciência e da tecnologia na resolução dos problemas humanos (QUEIROZ, 1986). A formação da medicina moderna se deu a partir de sua subordinação ao desenvolvimento capitalista, o que gerou profundas transformações políticas, econômicas e sociais (BATISTELLA, 2007). Em função disso, o campo da saúde vem sendo marcado pela constante presença de grupos de pressão, devido à variedade e magnitude dos interesses envolvidos.

Nesse contexto, consolidou-se o favorecimento do setor privado na saúde que, no Brasil, predominou até a década de 1980. De acordo com COHN et al (2010, p. 18): "esse processo de privatização da esfera pública, não exclusivo da saúde, tem como consequência o prevalecimento da lógica do lucro e da capitalização nos investimentos do setor". Exemplo dessa lógica de capitalização e lucratividade é a supervalorização e apologia a um modelo de assistência à saúde de alta densidade tecnológica, fundamentada basicamente nos procedimentos diagnósticos e terapêuticos.

Conceitualmente, a finalidade do trabalho em saúde deve ser o cuidado com o ser humano, um cuidado holístico e multidimensional, mas na sociedade moderna, delineada pelo poder do capital e pelo fetichismo da mercadoria, a tecnologia, mais que um meio, tem sido considerada como um fim em si mesma. "Há uma autonomização da tecnologia, os seres humanos perdem o governo da técnica e tornam-se altamente dependentes da tecnologia" (LORENZETTI et al., 2012, p. 437).

É possível identificar o desenvolvimento de uma cultura que vincula satisfação, segurança, dignidade e qualidade de vida ao acesso às tecnologias modernas. Isso gera nas pessoas uma falsa necessidade de consumo do novo, incluindo desde um telefone de última geração ou um veículo até o consumo de medicamentos ou exames sofisticados.

A consolidação do modelo biomédico no Brasil alimentou consideravelmente o fenômeno da medicalização, que pode ser entendido como "a crescente e elevada dependência dos indivíduos e da sociedade para com a

TrabalhoNecessário- www.uff.br/revistatrabalhonecesario: ano 16, №29/2018 
oferta de serviços e bens de ordem médico-assistencial e seu consumo cada vez mais intensivo" (BARROS, 2002, p. 77).

Ainda, segundo o autor citado:

$\mathrm{Na}$ medida em que o acesso ao consumo foi convertido no objetivo principal para o desfrute de níveis satisfatórios de bemestar, bons níveis de saúde passaram a ser vistos como possíveis na estreita dependência do acesso a tecnologias diagnósticoterapêuticas. A eficácia e efetividade das mesmas passam a confundir-se com seu grau de sofisticação (BARROS, 2002, p. 76).

Assim, durante muitas décadas, a atenção à saúde foi centrada na supervalorização da rede hospitalar, na hiperespecialização profissional, na fragmentação do cuidado, na desarticulação entre os diferentes profissionais de saúde, na falta de autonomia e engajamento dos sujeitos e na fragmentação da formação profissional (PAIM, 2009).

Esse cenário começou a sofrer as primeiras mudanças a partir da década de 1970, visando um novo modelo de atenção à saúde. Esse modelo foi influenciado pela Declaração de Alma-Ata, de 1978, que definiu a atenção básica ou primária como estratégia de promoção de saúde para todos; pelos movimentos reformistas no Brasil, que culminaram na criação do Sistema Único de Saúde (SUS) em 1988; e pela lei 8080/90 que determina, dentre outras questões, a mudança nas formas de realizar ações de saúde, mudanças no campo da formação dos profissionais de saúde e consolidação de um novo contexto de saúde no país (BRASIL, 2002a; GIL, 2005).

O SUS, provavelmente em decorrência de sua idealização no seio de movimentos populares, representa, em vários aspectos, uma proposta contra hegemônica baseada em princípios de justiça social. Para Gouveia e Palma (1999, p. 141), apesar das dificuldades encontradas na operacionalização do sistema, o SUS constitui "[...] a mais importante e avançada política social em curso no país. E seu caráter público, universal, igualitário e participativo é um interessante exemplo [...] de uma proposta democrática e popular de reforma do Estado".

Esse novo contexto de atenção à saúde exige mais do que um mero prestador de serviços de saúde, exige um profissional capaz de compreender as

TrabalhoNecessário- www.uff.br/revistatrabalhonecesario: ano 16, №29/2018 
concepções e diretrizes do SUS e considerá-las de fato em sua prática diária. O SUS defende a formação de um profissional apto a atuar de forma crítica, articulando a dimensão técnica à dimensão política e social no atendimento às necessidades de saúde das pessoas e das populações, incentivando o desenvolvimento da autonomia e a emancipação dos sujeitos.

Nesse cenário de mudança, o papel do profissional de saúde tem sido resignificado na perspectiva da atenção integral à saúde e, consequente, a formação em saúde passou a ser cada vez mais questionada a partir da constatação de que grande parte das instituições de ensino ainda prioriza o conhecimento científico fragmentado em disciplinas e/ou especialidades, a racionalidade, o desempenho individual e a dicotomia entre teoria e prática (BRASIL, 2008).

Em sintonia com a perspectiva de atuação desejável no âmbito do SUS, o Ministério da Saúde (MS) tem apresentado iniciativas de aproximações com as instituições formadoras, buscando contribuir com propostas na reorientação da formação profissional em saúde. Segundo o MS, a formação de profissionais para atuar na área da saúde deve ter como objetivo a capacidade de prestar cuidado às várias necessidades de saúde das pessoas e das coletividades. A melhor síntese para esta designação à educação dos profissionais de saúde é a noção de integralidade.

A atenção integral à saúde implica na ampliação dos referenciais com que cada profissional de saúde trabalha na construção de seu repertório de compreensão e ação; pressupõe práticas inovadoras em todos os espaços de atenção à saúde, práticas em diferentes cenários e conhecimento da realidade de vida das pessoas, das determinações sociais do processo saúde-doença, bem como de todos os âmbitos do sistema de saúde (BRASIL, 2004a).

Partindo da afirmação de que as diversas instâncias relacionadas com a construção e consolidação do SUS, entre elas as instituições de ensino, devem contribuir com as mudanças no campo das práticas e da formação profissional (CECCIM; FEUERWERKER, 2004) e que a articulação e cooperação entre os campos da educação e da saúde são indispensáveis para que se possam formular estratégias organizativas entrelaçadas com os princípios de mudanças no âmbito da formação de profissionais para o SUS, torna-se importante a

TrabalhoNecessário- www.uff.br/revistatrabalhonecesario: ano 16, №29/2018 
realização de trabalhos que investiguem os fundamentos dessa formação, a fim de fortalecer o debate sobre as mudanças necessárias na formação profissional em saúde.

A presente pesquisa buscou contribuir com esse debate e teve como objetivo geral identificar e compreender as concepções de homem e de sociedade que embasam os projetos de formação dos cursos de graduação da área da saúde da Universidade Federal de Goiás - UFG - Regional Jataí, assim como a abordagem sobre o tema mundo do trabalho presente nesses projetos.

Trata-se de uma reflexão originada dos resultados obtidos na dissertação de mestrado, uma pesquisa documental, que teve como objeto de estudo os Projetos Pedagógicos de Curso (PPC) dos cursos de graduação da área da saúde da UFG - Regional Jataí. O Projeto Pedagógico de um curso é o planejamento de como se deve organizar, estruturar e conduzir o processo de formação, para que se alcance o objetivo de formar os alunos numa determinada perspectiva desejada. Então, para a construção do Projeto Pedagógico de um curso, faz-se necessário questionar sobre que indivíduo se quer formar e para o que se quer formar, e o projeto definirá como formar.

Por este caráter atribuído ao PCC, de norteador da formação, optou-se pela análise desse documento na dissertação. Considerando que o Projeto Pedagógico de Curso não é um elemento neutro, tornou-se possível apreender dele as concepções que balizam a formação e sua intencionalidade explicita e implícita, ou seja, o projeto de formação de um curso.

Optou-se por estudar os cursos de graduação da área da saúde da UFG Regional Jataí, partindo do pressuposto de que as singularidades podem refletir a universalidade. A Regional Jataí da Universidade Federal de Goiás constitui um dos marcos da descentralização do ensino superior no estado de Goiás. Criada em 1980, reúne em 201725 cursos de graduação, nas áreas de humanas, exatas, biológicas, agrárias e mais recentemente, da saúde, além de cursos de Pós-Graduação (especialização, mestrado e doutorado).

Foram, então, incluídos na pesquisa documental os Projetos Pedagógicos de Curso (PPCs) dos cursos de graduação da área da saúde da UFG Regional Jataí: Biomedicina (UNIVERSIDADE FEDERAL DE GOIÁS, 2010a); Educação Física - modalidade Bacharelado (UNIVERSIDADE FEDERAL DE GOIÁS,

TrabalhoNecessário- www.uff.br/revistatrabalhonecesario: ano 16, №29/2018 
2010b); Fisioterapia (UNIVERSIDADE FEDERAL DE GOIÁS, 2011a); Enfermagem (UNIVERSIDADE FEDERAL DE GOIÁS, 2011b); e Medicina (UNIVERSIDADE FEDERAL DE GOIÁS, 2015).

Foram consultadas também as Diretrizes Curriculares Nacionais (DCN) para os cursos de graduação da área da saúde que, legalmente, devem embasar os projetos de formação destes cursos: Graduação em Biomedicina (BRASIL, 2003); Graduação em Educação Física (BRASIL, 2004b); Graduação em Enfermagem (BRASIL, 2001a); Graduação em Fisioterapia (BRASIL, 2002b); e Graduação em Medicina (BRASIL, 2001b; 2014). Todos os documentos analisados são de domínio público.

Considerando que o desejo desde o início era a compreensão do objeto em sua história, movimento, essência, complexidade e totalidade, optou-se pelo método do materialismo histórico-dialético.

No método escolhido, todas as análises foram guiadas pelo entendimento de que a realidade só poderá ser compreendida, sem o risco de reducionismo ou superficialidade, por meio da compreensão das relações materiais que lhe deram origem, ou seja, não se pode separar o objeto da dinâmica sócio-histórica que definiu seus contornos, dos condicionamentos históricos que influenciaram as relações sociais dos homens na produção material da existência:

Os pressupostos de que partimos não são arbitrários, nem dogmas. São pressupostos reais de que não se pode fazer abstração a não ser na imaginação. São os indivíduos reais, sua ação e suas condições materiais de vida, tanto aquelas por eles já encontradas quanto as produzidas por sua própria ação. Esses pressupostos são, pois, verificáveis por via puramente empírica (MARX; ENGELS, 2009, p.13).

Foi a partir da interrogação do objeto, em sua essência, que surgiram as categorias de análise, ou seja, o método guiou a investigação do objeto apontando os percursos metodológicos necessários para sua compreensão concreta:

Essa reflexão é sempre uma reflexão crítica, porque submete toda interpretação preexistente à análise. Na medida em que uma explicação adere ao objeto e é absorvida por este, passando a fazer parte intrínseca dele, ela também precisa ser submetida à 
análise. Não se trata simplesmente de opor ou substituir interpretações. Trata-se de ir até ao fundo das relações, processos e estruturas, apanhando, inclusive e necessariamente, as representações ideológicas ou teóricas construídas sobre o objeto e impregnadas nele (IANNI, 1988, p. 15).

Na pesquisa em questão, no percurso de compreensão do objeto, mostrouse necessária a pesquisa documental sobre os cursos de graduação. Assim, a partir da análise dos documentos, da reflexão e abstração de suas concepções e a partir do movimento dialético do objeto e de seu contexto sociohistórico, a pesquisa foi tomando corpo.

\section{Concepções da formação em saúde: da aparência à essência}

As Diretrizes Curriculares Nacionais (DCN) para os cursos de graduação da área da saúde especificam como perfil de egresso um profissional com formação generalista, humanista, crítica e reflexiva, capacitado para atuar nos diferentes níveis de atenção à saúde. Este perfil de egresso foi citado nos PPCs dos cursos de Biomedicina, Enfermagem, Fisioterapia e Medicina. Contudo, as contradições são evidentes, e as concepções que embasam os projetos não favorecem essa formação 'generalista, humanista, crítica e reflexiva'.

A concepção de homem predominante nos projetos de formação é a de um ser condicionado pelo meio físico-social, em que o homem ideal é aquele produtivo e adaptado à sociedade e ao mercado de trabalho. Seguem exemplos retirados do PPCs do Curso de Biomedicina:

\footnotetext{
Atuar multiprofissionalmente, interdisciplinarmente e transdisciplinarmente com extrema produtividade na promoção da saúde baseado na convicção científica, de cidadania e de ética (UNIVERSIDADE FEDERAL DE GOIÁS, 2010a, p. 10, grifo nosso).

O projeto de curso estará em contínua avaliação pelo Núcleo Docente Estruturante que deverá apresentar propostas de readequação sempre que se fizer necessário. A percepção dos alunos, as novas perspectivas de mercado, os avanços tecnológicos e também as novas legislações deverão sempre pautar a atualização do projeto de curso (UNIVERSIDADE FEDERAL DE GOIẢS, 2010a, p. 16, grifo nosso).
} 
Cabe destacar outro trecho desse mesmo projeto de formação, em que há menção da expressão 'mundo do trabalho':

A elaboração deste projeto teve como fonte inspiradora princípios educacionais básicos que consideram a educação um instrumento de transformação social, preparando o indivíduo para o mundo do trabalho, sempre considerando o desenvolvimento de sua consciência crítica frente aos problemas da sociedade (UNIVERSIDADE FEDERAL DE GOIÁS, 2010a, p. 83, grifo nosso).

Aparece a ideia de que mundo do trabalho é concebido no projeto como sinônimo de mercado de trabalho, pois ambas as expressões são alternadas no texto aleatoriamente. Contudo, a essência dos projetos denuncia uma formação voltada aos interesses de mercado e não traz elementos que sugiram a possibilidade de abordar a dimensão e complexidade do mundo do trabalho.

Excetua-se o projeto de formação do Curso de Educação Física, que se apresenta uma concepção de homem diferente da dos demais cursos ao defender enfaticamente o respeito à multiculturalidade, a valorização dos diferentes saberes, a emancipação dos sujeitos, e a ênfase na formação humana, como se percebe no trecho a seguir:

Trata-se de uma proposta de formação que visa assegurar o domínio de conhecimentos ético-político-cultural, voltados para formar homens e mulheres com autonomia para agir profissional e socialmente, sendo capazes de atuar conscientemente em defesa de uma formação humana que leve em conta a vida pessoal e social (UNIVERSIDADE FEDERAL DE GOIÁS, 2010b, p.7).

A concepção de mundo/sociedade é, de modo geral, individualista, inculcando a ideologia de que as desigualdades podem ser superadas a partir do esforço individual, do estudo e trabalho, de modo que, a partir desse esforço individual, todos poderiam galgar posições no mercado de trabalho e alcançar o tão sonhado sucesso pessoal e profissional. Seguem exemplos retirados, respectivamente, dos PPCs dos Cursos de Enfermagem e Medicina:

Comprometer-se com o autodesenvolvimento e o processo de formação e qualificação continuada dos trabalhadores de 
enfermagem, tendo em vista a excelência do exercício profissional (UNIVERSIDADE FEDERAL DE GOIÁS, 2011b, p. 7).

Os profissionais devem estar aptos a tomar iniciativas, fazer o gerenciamento e administração tanto da força de trabalho quanto dos recursos físicos e materiais e de informação, da mesma forma que devem estar aptos a serem empreendedores, gestores, empregadores ou lideranças na equipe de saúde. (UNIVERSIDADE FEDERAL DE GOIÁS, 2015, p. 63, grifo nosso).

Essa visão não reconhece o mundo/sociedade enquanto espaço contraditório, de relações sociais historicamente tecidas, não reconhece a luta de classes e a relação oprimido-opressor. É uma visão que dificulta a real compreensão da concepção ampliada de saúde, pois a partir dela a tendência é conceber a saúde enquanto bem individual, passível de ser "adquirido" pelos sujeitos desde que se esforcem e se adequem aos estilos de vida saudáveis, desconsiderando que as compreensões e ações no campo da saúde são resultantes de relações conflituosas e de múltiplas determinações.

Cabe destacar o projeto de formação do Curso de Biomedicina, que embora também faça menção à adoção de uma formação com caráter humanista, é o que mais se distancia dessa formação. É o único curso, dentre os pesquisados, que não possui na grade curricular nenhuma disciplina da área de ciências humanas e sociais e é o projeto que apresenta o maior alinhamento com a formação para o mercado de trabalho, para o empreendedorismo, para a adaptação à sociedade:

O curso de Biomedicina propõe uma formação pautada em princípios éticos e na compreensão da realidade social, cultural e econômica do seu meio, dirigindo sua atuação para a transformação da realidade em benefício da sociedade através da interação harmônica com os vários segmentos da comunidade local, regional e nacional (UNIVERSIDADE FEDERAL DE GOIÁS, 2010a, p. 9, grifo nosso).

Essa sugestão de transformação social por meio da interação harmônica entre os vários segmentos da sociedade ignora as relações historicamente tecidas e a luta de classes. Não se trata de transformação e sim de adaptação. Essa visão dificulta a real compreensão do conceito ampliado de saúde e tende a afastar a formação de um caráter humanista e crítico.

TrabalhoNecessário- www.uff.br/revistatrabalhonecesario: ano 16, №29/2018 
As metodologias de ensino presentes nos projetos de formação buscam se alinhar, de modo geral, à proposta das DCN, fundamentada na pedagogia das competências e nas metodologias ativas de ensino-aprendizagem.

De acordo com Martins (2012), a definição de competência é imbuída de vinculação entre a construção do conhecimento e a realidade e a prática social, o que é positivo; por outro lado pretere a base valorativa dessa prática social, abrindo espaço para que predominem os valores do mercado, o que, na realidade, implica na produção de um modelo de competências às avessas.

Desse modo, a pedagogia das competências possui uma dupla face: é válida enquanto incentivadora da autonomia e protagonismo do aluno, enquanto valorizadora da articulação da realidade e da prática como base para a construção do conhecimento; contudo, quando se constrói competências sem antes definir claramente para que e a serviço de quem, há uma grande possibilidade de que estas vislumbrem apenas o atendimento às novas demandas do mercado e o ajuste dos indivíduos à exploração capitalista.

\begin{abstract}
A tensão já mencionada em relação à noção de competência estende-se às próprias funções da educação, que indiscutivelmente não pode perder de vista a tarefa de preparar os indivíduos para a produção social, mas, da mesma forma, não pode perder de vista a tarefa de preparar os indivíduos para a produção de si mesmos como seres universais e livres, ou seja, preparados para a luta contra a produção social alienada (MARTINS, 2012, p. 70).
\end{abstract}

O problema não é a formação para o trabalho em si, uma vez que é por meio do trabalho que o homem garante a existência não só da vida individual, mas também da vida coletiva, social. O homem é parte da natureza e só pode sobreviver por meio do constante metabolismo com ela, por meio do trabalho (MARX; ENGELS, 2009). A perspectiva gramsciana também toma o trabalho como princípio educativo, considerando que ao mesmo tempo em que se produz trabalho, se produz cultura. O problema, então, é a formação voltada para o mercado de trabalho, para o capital, para o trabalho alienado e desumanizador.

A tendência que tem se apresentado mais forte na pedagogia das competências é a que enfatiza o desenvolvimento de sujeitos que privilegiam seus projetos pessoais de profissionalização em detrimento de outra perspectiva, 
em que a profissionalidade resulta de construções e compromissos coletivos dos trabalhadores.

Comparece, então, uma formação que apresenta o mercado de trabalho como sendo o mundo do trabalho em si, como sendo a totalidade e tudo o que é possível e desejável. Percebe-se nos trechos abaixo, extraídos dos PPCs dos Cursos de Enfermagem, Medicina e Fisioterapia, que a lógica de mercado e de sucesso profissional individual está presente, encoberta pelo véu da ideologia do empreendedorismo.

Um dos princípios norteadores da formação: os profissionais devem estar aptos a tomar iniciativas, fazer o gerenciamento e administração tanto da força de trabalho quanto dos recursos físicos e materiais e de informação, da mesma forma que devem estar aptos a serem empreendedores, gestores, empregadores ou lideranças na equipe de saúde (UNIVERSIDADE FEDERAL DE GOIÁS, 2011b, p. 8; UNIVERSIDADE FEDERAL DE GOIÁS, 2015, p. 63, grifo nosso).

Capacitar o futuro profissional para o exercício de competências e habilidades gerais de atenção à saúde, tomada de decisão, liderança, gestão e empreendedorismo e educação permanente, relacionados à prática da Fisioterapia (UNIVERSIDADE FEDERAL DE GOIÁS, 2011a, p. 11, grifo nosso).

Duarte (2010) destaca que a pedagogia das competências é imbuída de uma visão idealista de educação. Idealista na medida em que concebe os problemas sociais como resultados de equívocos aleatórios, levando a crença de que a mera difusão de novas ideias entre os indivíduos, por meio da educação, é capaz de resolver os problemas sociais. Ou seja, não há nenhuma perspectiva de compreensão e possibilidade de superação do modo de reprodução capitalista. Ainda de acordo com o autor, "Esse idealismo chega ao extremo de acreditar ser possível formar, no mesmo processo educativo, indivíduos preparados para enfrentar a competitividade do mercado e imbuídos do espírito de solidariedade social." (p. 35).

O modelo de competências é uma via de mão dupla e há uma significativa tendência de que as competências sejam desenvolvidas para atender apenas ao mercado de trabalho. Diverge, portanto, da concepção dialética de educação presente no SUS, que propõe o desenvolvimento das múltiplas capacidades do 
ser humano, o fortalecimento da consciência de classe para intervir de modo crítico, organizado e criativo na transformação estrutural da sociedade.

Todos os projetos de formação analisados falam em formação ética, com ênfase na humanização, solidariedade e reconhecimento da função social do profissional de saúde. Contudo, De Sordi e Bagnato (1998) alertam que, no contexto da formação hegemônica, para o mercado, a grande maioria dos egressos da área da saúde saem da universidade capacitados para demonstrar suas habilidades cognitivas e técnicas e, ao mesmo tempo, sua pequena familiaridade com as questões sociais. A maioria deles mostra-se desapegada dos compromissos éticos e bem adaptados a uma hierarquia social na qual o que importa é competir, vencer individualmente e ter sucesso na carreira.

A racionalidade que conduz as relações sociais, na perspectiva da manutenção da ordem capitalista, reifica os sujeitos e intensifica a destruição de vínculos entre eles. Nesse cenário, as subjetividades se constroem focadas no imediatismo, no efêmero, no fragmentário e na insensibilidade perante o outro. É importante que os profissionais de saúde em formação compreendam esse cenário, concebendo o individualismo como um produto da sociedade capitalista, em que o valor está centrado na produção de mercadorias.

Essa ideologia individualista dificulta a compreensão da dimensão, da complexidade e da importância do trabalho em equipe e multiprofissional. Para além do individualismo há ainda o corporativismo profissional que, seguindo a mesma lógica, incentiva que as diferentes categorias profissionais se apoiem internamente, mas entrem em competição com outras categorias por reconhecimento, por direito de executar procedimentos privativamente, dentre outros.

O individualismo e o corporativismo dificultam a construção da cidadania, pois se perde a noção de coletividade e de interdependência; confrontam diretamente a compreensão do conceito ampliado da saúde, uma vez que a tendência é a culpabilização dos indivíduos, como únicos responsáveis por suas condições de saúde ou de doença, dificultando aos alunos a compreensão dos conceitos de determinação social do processo saúde-doença, de saúde coletiva, de corresponsabilidade, de vínculo, de construção coletiva, de solidariedade, de integralidade.

TrabalhoNecessário- www.uff.br/revistatrabalhonecesario: ano 16, №29/2018 
Assim, embora os projetos de formação analisados abordem como desejável a formação política dos alunos e tragam a formação ética e a função social do profissional como um dos princípios norteadores da formação, apresentam concepções de homem e de sociedade que contradizem essa formação e deixam transparecer as ideologias de produtividade, sucesso individual e empreendedorismo, características estas que tendem a alinhar a formação com o mercado de trabalho da sociedade capitalista e encobrir a real dimensão do mundo do trabalho.

\section{Considerações finais}

A educação pode ser utilizada como meio de promoção da dominação ou libertação dos indivíduos. No âmbito da dominação interessa formar indivíduos dependentes, não críticos, não questionadores, acomodados ao modelo de sociedade e de produção vigentes. No âmbito do incentivo à libertação espera-se uma formação de indivíduos críticos, independentes, questionadores, capazes de refletir e atuar sobre a realidade. Assim, a formação crítica exige tomada de consciência, tomada de posição.

O fortalecimento do pensamento crítico e político na formação em saúde é indispensável para a ampliação da visão de mundo dos futuros profissionais da saúde, ultrapassando o conhecimento técnico-científico e resgatando conceitos como cidadania, justiça social e solidariedade. É necessário apresentar ferramentas para que estes futuros trabalhadores da saúde possam refletir sobre sua própria prática, conceber um projeto de sociedade e lutar por ele, incluindo a luta pelo direito a uma assistência à saúde pública e de qualidade, pois dificilmente haverá mudanças nas práticas de atenção a saúde sem a participação ativa dos profissionais enquanto sujeitos comprometidos com a cidadania, com a ética, com a democracia, com a coletividade e com o fortalecimento do sistema público de saúde.

Mesmo reconhecendo as iniciativas legais de mudança e reestruturação da formação em saúde como um importante avanço, é preciso ponderar que a proposta de modelos diferenciados, por si só, não altera paradigmas, se as concepções continuarem arraigadas nas formas antigas, como: relação

TrabalhoNecessário- www.uff.br/revistatrabalhonecesario: ano 16, №29/2018 
assimétrica e hierárquica professor $\mathrm{e}$ aluno, $\mathrm{e}$ entre profissional $\mathrm{e}$ indivíduo/comunidade; valorização apenas do saber profissional; abordagem centrada nos aspectos biológicos do ser humano e nas doenças; e visão individualista do ser humano e da sociedade.

São necessárias condições para que os alunos possam se apropriar de elementos que os qualifiquem a partir de uma formação duplamente densa: tanto no plano técnico, quanto no plano ético, humano, social e político. Assim, para que se possa efetivar uma formação em saúde coerente com os princípios e propostas do SUS, preparando de fato os alunos para atuarem nesse sistema de saúde, são necessárias rupturas profundas, na essência e estrutura da formação, repensando, primeiramente, sobre as concepções que tem balizado a formação em saúde e a práxis no SUS.

Além disso, a instituição universitária, tida como espaço de formação, de debate, de pensamento crítico e de compromisso com a sociedade tem, muitas vezes, desempenhado papel oposto, ao ser conivente com uma formação acrítica, que atende em grande parte aos interesses de mercado em detrimento do real comprometimento com a formação humana e com a sociedade. Diante destas diversas iniciativas de aproximação, dos diversos estudos apontando a necessidade de reorientação da formação em saúde para atuação profissional no SUS, os avanços materializados nesse sentido ainda são incipientes, denunciando a dificuldade da instituição universitária em atuar numa perspectiva contra hegemônica e abrindo um leque de possíveis reflexões e questionamentos sobre a complexidade das determinações envolvidas nesse processo.

\section{Referências}

BARROS, José Augusto Cabral. Pensando o processo saúde doença: a que responde o modelo biomédico? Saúde e Sociedade, São Paulo, v. 11, n.1, p. 6784, 2002.

BATISTELLA, Carlos. Abordagens contemporâneas do conceito de saúde. In: FONSECA, Angélica Ferreira; CORBO, Ana Maria D’Andrea (Orgs.). O território e o processo saúde-doença. Rio de Janeiro: EPSJV; FIOCRUZ, 2007. p.51-86. Disponível em: <http://www.retsus.fiocruz.br/upload/documentos/territorio_ e_o_processo_2_livro_1.pdf\#page=51 >. Acesso em: 20 set. 2014. 
BRASIL. Ministério da Educação. Conselho Nacional de Educação. Câmara de Educação Superior. Resolução CNE/CES 3/2001. Institui Diretrizes Curriculares Nacionais do Curso de Graduação em Enfermagem. Diário Oficial da União, 09 nov. 2001a.

. Ministério da Educação. Conselho Nacional de Educação. Câmara de Educação Superior. Resolução CNE/CES 4/2001. Institui Diretrizes Curriculares Nacionais do Curso de Graduação em Medicina. Diário Oficial da União, 09 nov. $2001 b$.

. Ministério da Saúde. Revista Brasileira de Saúde da Família, Brasília, DF, ano II, n. 5, Edição Especial, 2002a.

. Ministério da Educação. Conselho Nacional de Educação. Câmara de Educação Superior. Resolução CNE/CES 4/2002. Institui Diretrizes Curriculares Nacionais do Curso de Graduação em Fisioterapia. Diário Oficial da União, 04 mar. 2002b.

. Ministério da Educação. Conselho Nacional de Educação. Câmara de Educação Superior. Resolução CNE/CES 2/2003. Institui Diretrizes Curriculares Nacionais do Curso de Graduação em Biomedicina. Diário Oficial da União, 20 fev. 2003.

- Ministério da Saúde. Secretaria de Gestão do Trabalho e da Educação em Saúde. Departamento de Gestão da Educação na Saúde. Aprender SUS: o SUS e os cursos de graduação da área da saúde. Brasília: DF, 2004a.

. Ministério da Educação. Conselho Nacional de Educação. Câmara de Educação Superior. Resolução CNE/CES 7/2004. Institui as Diretrizes Curriculares Nacionais para os cursos de graduação em Educação Física, em nível superior de graduação plena. Diário Oficial da União, 31 mar. 2004b.

- Conselho Nacional de Secretários de Saúde. A formação de profissionais de saúde em sintonia com o SUS. Brasília: CONASS, 2008. Disponível em: < http://www.cosemsms. org.br/files/publicações/formacao_profissionais_2008.pdf>. Acesso em: 17 set 2015.

. Ministério da Educação. Conselho Nacional de Educação. Câmara de Educação Superior. Resolução CNE/CES 3/2014. Institui Diretrizes Curriculares Nacionais do Curso de Graduação em Medicina e dá outras providências. Diário Oficial da União, 23 jun. 2014.

CECCIM, Ricardo Burg; FEUERWERKER, Laura Camargo Macruz. O quadrilátero da formação para a área da saúde: ensino, gestão, atenção e controle social. Physis: Revista de Saúde Coletiva, Rio de Janeiro, v. 14, n. 1, p. 41-65, 2004.

COHN, Amélia et al. A saúde como direito e como serviço. 6. ed. São Paulo: Cortez, 2010. 
DE SORDI, Mara Regina Lemes; BAGNATO, Maria Helena Salgado. Subsídios para uma formação profissional crítico-reflexiva na área da saúde: o desafio da virada do século. Revista latino-americana de enfermagem, Ribeirão Preto, v. 6, n. 2, p. 83-88, 1998.

DUARTE, Newton. O debate contemporâneo das teorias pedagógicas. In: MARTINS, Lígia Márcia; DUARTE, Newton (orgs). Formação de professores: limites contemporâneos e alternativas necessárias [online]. São Paulo: Editora UNESP; São Paulo: Cultura Acadêmica, 2010. Disponível em:

<http://books.scielo.org>. Acesso em: 12 dez. 2015.

GIL, Célia Regina Rodrigues. Formação de recursos humanos em saúde da família: paradoxos e perspectivas. Caderno de Saúde Pública, Rio de Janeiro, v.21, n.2, p. 490-98, 2005.

GOUVEIA, Roberto; PALMA, José João. SUS: na contramão do neoliberalismo e da exclusão social. Estudos Avançados, São Paulo, v. 13, n. 35, p. 139-146, 1999.

IANNI, Octávio. Dialética e capitalismo: ensaio sobre o pensamento de Marx. 3. ed. Petrópolis: Vozes, 1988.

LORENZETTI, Jorge et al. Tecnologia, inovação tecnológica e saúde: uma reflexão necessária. Texto \& Contexto Enfermagem, Florianópolis, v. 21, n. 2, p. 432-39, 2012.

MARTINS, Lígia Márcia. Da formação humana em Marx à crítica da pedagogia das competências. In: DUARTE, Newton (org). Crítica ao fetichismo da individualidade. 2. ed. Campinas: Autores associados, 2012. p. 53-74.

MARX, Karl; ENGELS, Friedrich. A ideologia alemã. São Paulo: Expressão popular, 2009.

PAIM, Jairnilson Silva. O que é o SUS? Rio de Janeiro: Editora Fiocruz, 2009.

QUEIROZ, Marcos de Souza. O paradigma mecanicista da medicina ocidental moderna: uma perspectiva antropológica. Revista de Saúde Pública, São Paulo, v. 20, n. 4, p. 309-17, 1986.

UNIVERSIDADE FEDERAL DE GOIÁS. Projeto Pedagógico do Curso de Biomedicina. Jataí, 2010a. . Projeto Político Pedagógico do Curso de Bacharelado em Educação Física. Jataí, 2010b. . Projeto Pedagógico do Curso de Fisioterapia. Jataí, 2011 a. 2011b. . Projeto Pedagógico do Curso de Graduação em Enfermagem. Jataí, 
Projeto Pedagógico do Curso de Graduação em Medicina. Jataí, 2015.

Recebido em: 27 de dezembro de 2018.

Aprovado em: 20 de março de 2018.

Publicado em: 13 de junho de 2018. 